Article

\title{
Current Practice of Surgery for Benign Goitre-An Analysis of the Prospective DGAV StuDoQ|Thyroid Registry
}

\author{
Detlef K. Bartsch ${ }^{1, *}$, Cornelia Dotzenrath ${ }^{2}$, Christian Vorländer ${ }^{3}$, Andreas Zielke ${ }^{4}$, \\ Theresia Weber ${ }^{5}$, Heinz J. Buhr ${ }^{6}$, Carsten Klinger ${ }^{6}$, Kerstin Lorenz ${ }^{7}$ and \\ the StuDoQ/Thyroid Study Group ${ }^{+}$ \\ 1 Department of Visceral-, Thoracic- and Vascular Surgery, Philipps-University Marburg, \\ 35043 Marburg, Germany \\ 2 Department of Endocrine Surgery, Helios University Hospital Wuppertal, 42283 Wuppertal, Germany; \\ cornelia.dotzenrath@helios-kliniken.de \\ 3 Department General and Endocrine Surgery, Bürgerhospital Frankfurt/Main, 60318 Frankfurt, Germany; \\ c.vorlaender@buergerhospital-ffm.de \\ 4 Department of Endocrine Surgery, Diakonie-Klinikum Stuttgart, 70176 Stuttgart, Germany; \\ andreas.zielke@diak-stuttgart.de \\ 5 Department of Endocrine Surgery, Katholisches Klinikum Mainz, 55131 Mainz, Germany; \\ t-weber@kkmainz.de \\ 6 German Society of General and Visceral Surgery (DGAV), 10117 Berlin, Germany; hbuhr@dgav.de (H.J.B.); \\ carsten.klinger@dgav.de (C.K.) \\ 7 Department of Visceral-, Vascular and Endocrine Surgery, University Medical Centre Halle, 06120 Halle, \\ Germany; kerstin.lorenz@uk-halle.de \\ * Correspondence: bartsch@med.uni-marburg.de \\ + Membership of the StuDoQ/Thyroid study group is provided in the Acknowledgments.
}

Received: 1 March 2019; Accepted: 4 April 2019; Published: 8 April 2019

check for updates

\begin{abstract}
Background: To evaluate the current indications, resection strategies and short-term outcomes of surgery for benign goitre in a country with endemic goitre. Methods: Data of patients who underwent surgery for benign goitre were retrieved from the prospective StuDoQ/Thyroid registry and retrospectively analysed regarding the patient's demographics, indications for surgery, surgical procedures, histology, and perioperative outcomes. Results: In a 15-month period, 12,888 patients from 83 departments underwent thyroid resections for benign conditions. Main indications for surgery were exclusion of malignancy (68\%), compression symptoms $(20.7 \%)$ and hyperthyroidism (9.7\%). Preoperative fine needle aspiration cytology was performed in only $12.2 \%$ of patients with the indication "exclusion of malignancy". Thyroidectomy $(49.8 \%)$ or hemithyroidectomy $(36.9 \%)$ were performed in $86.7 \%$ of patients. Minimally invasive or alternative surgical techniques were applied in only $2.2 \%$. Intraoperative neuromonitoring was used in $98.4 \%$ of procedures, in $97.5 \%$ of patients at least one parathyroid gland was visualized, and in $15.3 \%$ of patients parathyroid tissue was autografted, respectively. The rates of unilateral and bilateral transient recurrent nerve palsy were $3.6 \%$ and $0.07 \%$ of nerves at risk, the rate of transitory hypoparathyroidism was $15.3 \%$. The rates of postoperative bleeding and wound infections requiring reoperation were $1.4 \%$ and $0.07 \%$, respectively. Conclusions: The indication "exclusion of malignancy" is made too liberally, and there is a strong attitude to perform complete thyroid resections. Postoperative hypoparathyroidism is the major complication after surgery for benign thyroid disease, thus requiring more awareness.
\end{abstract}

Keywords: indication; thyroid resection; registry; recurrent laryngeal nerve palsy; hypoparathyroidism 


\section{Introduction}

Germany is an endemic goitre area and thyroid resections are among the most frequent visceral operations, with approx. 70,000 procedures being carried out per year $[1,2]$. Thyroid resections are performed by general surgeons, as well as specialized endocrine surgeons in hospitals of all care levels. National and international guidelines for thyroid surgery, including quality criteria, have been developed on the basis of retrospective cohort studies of specialized centres [3-7], since prospective randomized-controlled trails are largely missing. The German Society for General and Visceral Surgery (DGAV) established the StuDoQ/Thyroid registry in close cooperation with the German Society of Endocrine Surgeons (CAEK) for quality control in thyroid surgery to close the gap between the somewhat virtual world of prospective randomized trials, retrospective cohort studies of tertiary referral centres, and daily practice. Health data of insured persons are increasingly evaluated by health insurances to evaluate the quality and practice of thyroid surgery and to make it transparent to the public $[8,9]$. It has been shown by a retrospective analysis of insurance data that only $9 \%$ of patients with thyroid resections underwent preoperative calcitonin screening [8], suggesting that actual guideline recommendations [3-7] are not fully implemented in daily practice. It has also been shown that the resection strategy for benign goitre changed from subtotal resections to thyroidectomy in Germany between 2005 to 2011 [10]. However, recently, some experts have again made a plea for individualizing the extent of resection for endemic goitre instead of heading for routine total thyroidectomy [11].

Aim of the present study was to evaluate the current practice of thyroid surgery for benign goitre in Germany based on the StuDoQ/Thyroid registry, including the indication for operation, operative strategies and perioperative outcomes.

\section{Materials and Methods}

The StuDoQ/Thyroid Registry of the DGAV was designed as a prospective, multicentre database with web-based data entry. The register is managed by the DGAV and was developed in close cooperation with the board of the German Society of Endocrine Surgeons (CAEK). Relevant outcome and quality indicators were selected on the basis of the German S2k guidelines [3-5] for the surgical treatment of benign and malignant goitre, the certification guidelines for competence centres for thyroid/parathyroid surgery of the DGAV (www.dgav.de), and the EUROCRINE registry (https: //eurocrine.eu). 52 parameters were defined by a browser-based electronic case report form (eCRF). The registry was prospectively maintained since April 2017. Data from participating centres were entered in pseudonymized form at the institutional level without an over-institutional identifier in the prospective StuDoQ/Thyroid registry. The data were subject to an immediate automatic plausibility check with automatic error indication, which avoids many typical and predictable input errors.

All participating institutions have to approve the correct number of thyroid resections entered in the registry by a written confirmation of the hospitals' controller. In addition, the completeness and correctness of the data will be checked as part of the regular certification audits for the certified competence and reference thyroid centres of the DGAV.

All enrolled patients signed an informed consent for data collection, and approval for data management was obtained from the TMF (Technologie und Methodenplattform für die vernetzte medizinische Forschung).

For the present study, all patients who underwent thyroid resections for benign pathologies between 1 April 2017 and 6 July 2018 were extracted from the StuDoQ/Thyroid registry. Data were extracted in anonymised form and retrospectively analysed with respect to demographics, indication for surgery, types of surgical procedures, histology, and perioperative outcomes.

The fine needle aspiration cytology specimens were classified according to the Bethesda criteria [12]. The postoperative function of the recurrent laryngeal nerve was determined by laryngoscopy within the first 5 postoperative days by an independent head and neck specialist. Vocal cord immobility was defined as palsy, impaired, but notable vocal cord movement was defined as incomplete palsy. 
Both conditions were documented as dysfunction of the recurrent laryngeal nerve. Pre-existing recurrent laryngeal nerve palsies were excluded from the present analysis. The palsy rate was calculated per nerves at risk (NAR). The nerve dysfunction was defined as transient if it completely recovered within 6 months, and permanent if it persisted after 6 months. Postoperative hypoparathyroidism was defined as a serum level of intact parathormone $<15 \mathrm{pg} / \mathrm{L}$ and serum calcium $<2.1 \mathrm{mmol} / \mathrm{L}$ with the necessity of calcium substitution. The postoperative hypoparathyroidism was defined as transient, if it completely recovered within 6 months, after that time it was considered permanent.

\section{Statistical Analysis}

Continuous variables are presented as means (standard deviation) and categorical variables as proportions. Quantitative variables were compared using the Student's $t$-test and qualitative variables (e.g., gender) using the chi-square test or Fisher's exact test as appropriate. All reported probability values ( $p$-values) are based on two sided tests; the level of statistical significance was set at $p<0.05$. Analyses were performed using SPSS 23.0 (IBM, Chicago, IL, USA, 2017).

\section{Results}

A total of 17,702 patients from 83 surgical departments were entered into the StuDoQ/Thyroid Registry in the first 15 months. The data of 12,888 patients with benign goitre, who were discharged before 6 July 2018, were analysed. All levels of thyroid surgery care were represented, since 34\% $(n=29)$ of participating clinics operated on fewer than 50 patients, while $18 \%(n=15)$ of clinics operated on more than 300 patients per year (Table 1). Almost two thirds of patients $(62.9 \%, n=8102)$ were operated on in clinics that performed more than 300 procedures per year (Table 1).

Table 1. Number of thyroid procedures and operated entities of participating clinics.

\begin{tabular}{lcccc}
\hline $\begin{array}{c}\text { Number of Cases Per } \\
\text { Clinic (Clinics/\%) }\end{array}$ & $\begin{array}{c}\text { Multinodular } \\
\text { Goitre }(\boldsymbol{n = 9 0 6 9 )}\end{array}$ & $\begin{array}{c}\text { Graves' Disease } \\
(\boldsymbol{n}=\mathbf{9 2 5})\end{array}$ & $\begin{array}{c}\text { Other Entities * } \\
(\boldsymbol{n}=\mathbf{2 8 9 4})\end{array}$ & $\begin{array}{c}\text { All Entities } \\
(\boldsymbol{n}=\mathbf{1 2}, \mathbf{8 8 8})\end{array}$ \\
\hline $2-50(29 / 34 \%)$ & $255(2.8 \%)$ & $17(1.8 \%)$ & $105(3.6 \%)$ & $377(2.9 \%)$ \\
$51-100(17 / 20 \%)$ & $639(7 \%)$ & $66(7.1 \%)$ & $238(8.2 \%)$ & $943(7.3 \%)$ \\
$101-300(24 / 28 \%)$ & $2335(25.7 \%)$ & $272(29.4 \%)$ & $859(29.7 \%)$ & $3466(26.9 \%)$ \\
$>300(15 / 18 \%)$ & $5840(64.4 \%)$ & $570(61.6 \%)$ & $1692(58.4 \%)$ & $8102(62.9 \%)$ \\
total $(83 / 100 \%)$ & $9069(100 \%)$ & $925(100 \%)$ & $2894(100 \%)$ & $12,888(100 \%)$ \\
\hline
\end{tabular}

* including follicular adenoma, autonomous adenoma, regressive thyroid nodule, all forms of thyroiditis, c-cell hyperplasia and normal thyroid.

$74.1 \%(n=9550)$ women and $25.9 \%(n=3338)$ men with a median age of 55 (range 12-88) years underwent thyroid surgery. Only $61(0.47 \%)$ patients were younger than 18 years, and $1556(12.1 \%)$ patients were older than 70 years. $10.3 \%(n=1328)$ of patients (1048 women, 280 men) were overweight with a body mass index $>35$. A total of $13.3 \%(n=1714)$ patients had an increased perioperative risk, $13 \%(n=1671)$ of patients were classified as ASA3, and $0.3 \%(n=43)$ patients as ASA4.

The main indication for surgery was exclusion of malignancy in $68 \%(n=8762)$ of patients, followed by compression symptoms in $20.7 \%(n=2666)$ patients and hyperthyroidism in $9.7 \%(n=1248)$ patients (Table 2). 95.8\% $(n=12,347)$ of patients underwent initial surgery and $4.2 \%(n=541)$ patients had cervical reoperations on the affected side(s).

Preoperative calcitonin screening was performed in $62.6 \%(n=8068)$ of patients. A preoperative fine needle aspiration cytology (FNAC) was performed in only $12.2 \%(n=1068)$ of the 8762 patients with the main surgical indication "exclusion of malignancy". In $60(5.6 \%)$ of these patients, the FNAC result was cancer (Bethesda VI) or suspicion of malignancy (Bethesda V). In $22.9 \%(n=245)$ of these patients a follicular neoplasia (Bethesda IV), in 22,1\% $(n=236)$ atypia of unclear significance or a follicular lesion of unclear significance (Bethesda III) and in 32,9\% $(n=352)$ of these patients a benign finding was diagnosed, whereas in $15.2 \%(n=162)$ of these patients, the FNA was not diagnostic, respectively. 
Table 2. Main indication for thyroid surgery in histologically benign lesions.

\begin{tabular}{lcc}
\hline \multicolumn{1}{c}{ Main Indication for Surgery } & No. of Patients & $\mathbf{\%}$ \\
\hline Exclusion of malignancy & 8762 & 68.0 \\
Compression symptoms & 2666 & 20.7 \\
Hyperthyroidism & 1248 & 9.7 \\
Hyperparathyroidism & 154 & 1.2 \\
Redo surgery for benign finding & 58 & 0.4 \\
Total & 12,888 & 100 \\
\hline
\end{tabular}

Preoperative laryngoscopy for the assessment of vocal cord function was performed in $97.6 \%$ $(n=12,578)$ patients and normal results were obtained in $96.7 \%(n=12,462)$ of patients. $0.9 \%(n=116)$ patients had a unilateral palsy of the recurrent laryngeal nerve (RLNP), and $0.04 \%(n=4)$ patients had a bilateral RLNP.

The most frequently performed thyroid resections were either thyroidectomy $(49,8 \%, n=6386)$ or hemithyroidectomy $(36.9 \%, n=4768)$, accounting for more than $85 \%$ of operations (Table 3 ). The proportion of thyroidectomies was the highest in the case of Graves' disease, with $92.1 \%$.

Table 3. Extent of thyroid resections according to entity.

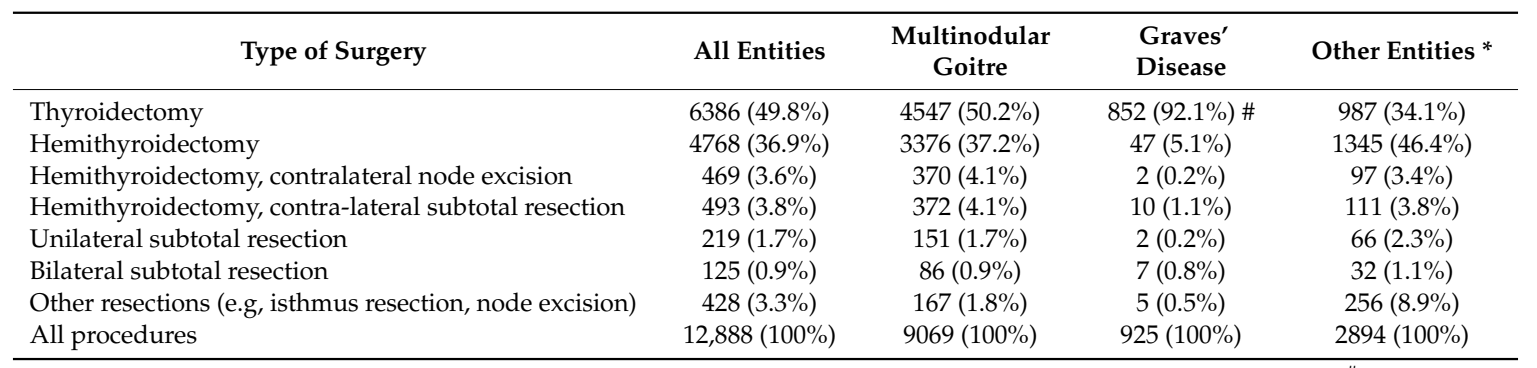

* includes, besides others, follicular adenoma, all forms of thyroiditis, c-cell hyperplasia, normal thyroid; ${ }^{*} p<0.05$

Graves' disease compared to multinodular goitre and other entities combined.

In $97.8 \%$ ( $n=12,602)$ of patients, conventional open surgery was performed, with minimally invasive video-assisted thyroidectomies (MIVAT) being performed in 2.2\% $(n=286)$ of patients. Robotic-assisted thyroidectomies or resections via a combined axillary breast access (ABBA) were an absolute exception, with 14 and $3(0.01 \%)$ procedures, respectively. Only $0.18 \%(n=24)$ of patients required a sternotomy for the resection of benign thyroid disease. The median operative time for hemithyroidectomy (75, range 22-380 $\mathrm{min}$ ) and thyroidectomy (109, range 42-384 $\mathrm{min}$ ) were similar compared to unilateral (63, range 18-265 $\mathrm{min}$ ) and bilateral subtotal resections (100, range 28-246 min, $p>0.05)$.

Visualisation of the recurrent laryngeal nerve (RLN)—as recommended in the guidelines—was performed in $99.8 \%(n=12,874)$ of patients. Intraoperative neuromonitoring (IONM) of the RLN was used in $98.4 \%(n=12,686)$ of patients, whereby intermittent IONM $(82.6 \%)$ was significantly more used than continuous IONM $(17.4 \%, p=0.02$, Table 4$)$. IONM of the superior laryngeal nerve, however, was only performed in $7.7 \%(n=997)$ of patients (Table 4$)$. In $97.5 \%(n=12,564)$ of patients, at least one parathyroid gland was identified intraoperatively, with no significant differences between the entities (Table 4). Autotransplantation of parathyroid tissue was undertaken in $15.3 \%(n=1875)$ of patients, most frequently after resections for Graves' disease, with 22.3\% (Table 4).

The median weight of resected nodular goitre specimens was 48 grams; $10.1 \%(n=916)$ weighted less than 10 grams, and $9.6 \%(n=874)$ more than 100 grams. Histopathological examination revealed the following main diagnoses: nodular goitre in $70.4 \%(n=9069)$ of patients, follicular adenoma in $14.1 \%(n=1817)$, Graves' disease in $7.2 \%(n=925)$ and other pathologies in $8.3 \%(n=1077)$ of patients, respectively. 
Table 4. Intraoperative neuromonitoring, visualisation and autotransplantation of parathyroids.

\begin{tabular}{lcccc}
\hline \multicolumn{1}{c}{ Procedure } & Total $(\boldsymbol{n = 1 2 , 8 8 8 )}$ & $\begin{array}{c}\text { Multinodular } \\
\text { Goitre }(\boldsymbol{n = 9 0 6 9 )}\end{array}$ & $\begin{array}{c}\text { Graves' Disease } \\
(\boldsymbol{n}=\mathbf{9 2 5})\end{array}$ & $\begin{array}{c}\text { Other Entities } \\
(\boldsymbol{n}=\mathbf{2 8 9 4})\end{array}$ \\
\hline $\begin{array}{l}\text { Neuromonitoring RLN } \\
\text { no }\end{array}$ & $202(1.6 \%)$ & $133(1.5 \%)$ & $13(1.4 \%)$ & $56(1.9 \%)$ \\
$\quad$ yes & $12,686(98.4 \%)$ & $8936(98.5 \%)$ & $912(98.6 \%)$ & $2837(98.1 \%)$ \\
$\quad \begin{array}{l}\text { intermittent IONM } \\
\text { continuous IONM }\end{array}$ & $10,488(82.6 \%)$ & $7430(83.1 \%)$ & $705(77.3 \%)$ & $2352(82.9 \%)$ \\
Neuromonitoring SLN & $2198(17.4 \%)$ & $1506(16.9 \%)$ & $207(22.7 \%)$ & $485(17.1 \%)$ \\
$\quad$ yes & $997(7.7 \%)$ & $623(6.9 \%)$ & & \\
no & $11,891(92.3 \%)$ & $8446(93.1 \%)$ & $858(92.8 \%)$ & $2587(89.4 \%)$ \\
\hline Identification PG & & & & \\
no & $324(2.5 \%)$ & $226(2.5 \%)$ & $6(0.6 \%)$ & $92(3.2 \%)$ \\
yes & $12,564(97.5)$ & $8843(97.5 \%)$ & $919(99.4 \%)$ & $2802(97.8 \%)$ \\
$\quad$ PG & $1043(8.1 \%)$ & $679(7.5 \%)$ & $12(1.3 \%)$ & $352(12.2 \%)$ \\
$\quad$ or more PG & $11,521(89.3 \%)$ & $8164(90 \%)$ & $907(98.1 \%)$ & $2450(84.7 \%)$ \\
\hline Autotransplantation PG & & & \\
$\quad$ yes & $1875(15.3 \%)$ & $1326(14.6 \%)$ & $206(22.3 \%)$ & $343(11.9 \%)$ \\
no & $11,013(84.7 \%)$ & $7743(85.4 \%)$ & $719(77.7 \%)$ & $2551(88.1 \%)$ \\
\hline
\end{tabular}

RLN-recurrent laryngeal nerve; SLN-external branch superior laryngeal nerve; PG-parathyroid gland;

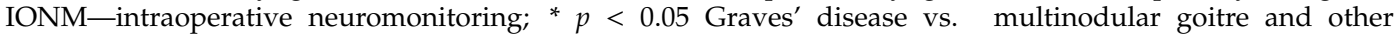
entities combined.

Postoperative laryngoscopy was performed in $95.6 \%(n=12,320)$ of patients. This revealed a dysfunction in 672 of 18793 (3.6\%) nerves at risk (NAR), with unilateral dysfunction in 658 (3.5\%) patients and bilateral dysfunction in $14(0.07 \%)$ patients (Table 5). The rate of RLNP was highest $(3.9 \%)$ after surgery for Graves' disease. At the evaluation date, 525 of the 672 NAR with early postoperative dysfunction should have had the 6-months follow-up laryngoscopy. This result was documented for $244(47 \%)$ NAR, and $119(48.8 \%)$ of examined nerves showed a permanent palsy. Based on these results, one can extrapolate a rate of permanent RLNP of about $1.4 \%$ per NAR.

Table 5. Postoperative complications.

\begin{tabular}{|c|c|c|c|c|}
\hline Parameter & $\begin{array}{l}\text { All Patients } \\
(n=12,888)\end{array}$ & $\begin{array}{c}\text { Multinodular } \\
\text { Goitre }(n=9069)\end{array}$ & $\begin{array}{c}\text { Graves' Disease } \\
\quad(n=925)\end{array}$ & $\begin{array}{c}\text { Other Entities } \\
\quad(n=2894)\end{array}$ \\
\hline \multicolumn{5}{|l|}{ Function RLN at discharge ${ }^{*}$} \\
\hline nerves at risk (NAR) & $18,793(100 \%)$ & $13,498(100 \%)$ & $1766(100 \%)$ & $3529(100 \%)$ \\
\hline not assessed & $833(4.4 \%)$ & $580(4.3 \%)$ & $48(2.7 \%)$ & $205(5.8 \%)$ \\
\hline normal referring to NAR & $17,288(92.0 \%)$ & $12,424(92.0 \%)$ & $1649(93.4 \%)$ & $3215(91.1 \%)$ \\
\hline dysfunction referring to NAR & $672(3.6 \%)$ & $494(3.7 \%)$ & $69(3.9 \%)$ & $109(3.7 \%)$ \\
\hline unilateral paralysis & $418(2.2 \%)$ & $299(2.2 \%)$ & $50(2.8 \%)$ & $69(2.3 \%)$ \\
\hline unilateral incomplete palsy & $240(1.3 \%)$ & $185(1.4 \%)$ & $15(0.9 \%)$ & $40(1.4 \%)$ \\
\hline bilateral paralysis & $4(0.02 \%)$ & $4(0.03 \%)$ & 0 & 0 \\
\hline bilateral incomplete palsy & $10(0.05 \%)$ & $6(0.05 \%)$ & $4(0.2 \%)$ & 0 \\
\hline \multicolumn{5}{|l|}{ Hypocalcemia with Ca substitution at discharge $\#$} \\
\hline yes & $1965(15.3 \%)$ & $1360(15 \%)$ & $263(28.4 \%)^{\$}$ & $342(11.9 \%)$ \\
\hline no & $10,923(84.7 \%)$ & $7709(85 \%)$ & $662(71.6 \%)$ & $2552(88.1 \%)$ \\
\hline Reop. for bleeding & $180(1.4 \%)$ & $104(1.4 \%)$ & $12(1.7 \%)$ & $20(1.4 \%)$ \\
\hline Reop. for wound infection & $10(0.07 \%)$ & $5(0.6 \%)$ & $1(0.1 \%)$ & 0 \\
\hline Reop. for other reasons (e.g., lymphatic fistula) & $6(0.04 \%)$ & $5(0.06 \%)$ & 0 & $1(0.07 \%)$ \\
\hline
\end{tabular}

A postoperative hypocalcemia with the necessity of calcium substitution was present at discharge in $15.3 \%$ ( $n=1965)$ of patients. The rate of postoperative transient hypoparathyroidism was significantly higher in patients with Graves' disease (28.4\%) than in patients with multinodular goitre $(15 \%)$ and other entities $(11,9 \%, p<0.05$, Table 5). A 6-month follow-up examination was documented for 
$1021(51.9 \%)$ patients at the evaluation date, $132(12.9 \%)$ of those showed a permanent postoperative hypoparathyroidism. Based on these data, a rate of permanent hypoparathyroidism of $1.5 \%$ to $3.5 \%$ depending on the operated entity can be calculated.

Reoperations for postoperative bleeding or wound infection had to be performed in $1.4 \%(n=180)$ and $0.07 \%(n=11)$ of patients (Table 5$)$.

\section{Discussion}

In 2013, approximately 72,000 thyroid surgeries were performed by 852 departments in Germany [9]. It can therefore be assumed that almost $10 \%$ of departments which perform thyroid resections in Germany entered their data in the StuDoQ/Thyroid registry and that about $15 \%$ of patients undergoing thyroid resections during the 15 -months evaluation period were recorded. Although this rate cannot be regarded as representative, since only a coverage rate of more than $20 \%$ is considered representative [13], clear trends with regard to indications, surgical standards and outcome quality of thyroid surgery can be derived from these prospective registry data.

The presented data clearly show a relatively radical attitude towards the extent of resection in benign thyroid pathologies, since more than three quarters of the operations were thyroidectomies or hemithyroidectomies. Partial thyroid resections, especially nodule-oriented partial resections, play only a minor role. Already between 2005 and 2011, the rate of total thyroidectomies and hemithyroidectomies had increased from $37 \%$ to $73 \%$, while the rate for partial or subtotal resections decreased by about $60 \%$ [10]. This is obviously an ongoing worldwide tendency, although recently some experts have made a plea for individualizing the extent of resection in endemic goitre instead of heading for routine thyroidectomy [11].

The presented data also show that minimally invasive thyroid resections or alternative approaches such as robotic-assisted thyroidectomy currently play only a marginal role in Germany with about $2 \%$ of all interventions. This is in contrast to the impressions promoted by some media and the relatively high number of reports on alternative approaches for thyroid resections in recent years.

It is often critically noted that, especially in Germany, thyroid resections are indicated too liberally for so-called "cold", potentially malignant nodules, since the preoperative tools recommended in the guidelines for determining the risk of malignancy are not completely used [2,14]. In the present study, the main indication for surgery was "exclusion of malignancy" in two thirds of patients, but a preoperative FNAC was performed in only $12 \%$, and a preoperative calcitonin screening in only $60 \%$ of these patients. Thus, current guideline recommendations [3-7] are not well implemented across the country. This underscores a previous retrospective insurance data analysis of 25,600 patients with nodular goitre [8]. This study demonstrated that more than a quarter of the operations (approx. 20,000) in Germany were performed because of "suspicious" thyroid nodules, but the preoperative calcitonin screening and a FNAC were performed in only $9 \%$ and $21 \%$ of patients, respectively [8]. Since the indication for surgery in potentially suspicious thyroid nodules is also significantly triggered by the patient, further efforts should be undertaken to educate patients, despite a more consistent use of the diagnostic options by the physicians.

The operative standards in participating clinics of the registry were high. The RLN was visualised in almost every operation, and IONM was used in more than $98 \%$ of procedures for the potential protection of the RLN, although IONM is not recommended in the guidelines [3-7]. This result confirms the data from a questionnaire survey conducted in 2012, where IONM was already used in $91 \%$ of thyroidectomies in Germany [15]. However, continuous IONM was used in only $17.4 \%$, less than expected, although it might be superior to the intermittent IONM with regard to the real-time detection of traction injury of the RLN [16]. In more than $98 \%$ of all interventions, at least one parathyroid gland was identified and an autotransplantation of devascularized parathyroids was routinely performed as required by the guidelines [3-7]. 
The StuDoQ/Thyroid registry also seems to realistically reflect the complication rates. The rate of transient RLNP is $3.6 \%$, with reference to NAR, and is thus somewhat higher than in previous European registry studies, with $2.9 \%$ and $3.5 \%[17,18]$, but lower than the $6.9 \%$ rate in a German prospective randomized multicentre study CLIVIT [19] conducted at 13 institutions. However, only 14 (0.07\%) patients experienced a bilateral RLNP, which is in the lower range of the more recent literature [19-23]. In $51 \%$ of the patients who were re-examined after 6 months, the RLNP had completely recovered. Thus, one can extrapolate a rate of permanent RLNP of $1.4 \%$ for the total cohort, which is in the middle range of the RNLP rates (0.9-2.9\%) reported in prospective randomized trials [10,19,21-23].

The rate of transient postoperative hypoparathyroidism at discharge was comparatively high, with $15.3 \%$ in the total collective [10,19-23], whereby the rate was highest after surgery for Graves' disease. Independent of the entity, at least $80 \%$ of patients who had already had a 6-months follow-up examination showed a complete recovery of the parathyroid function. Thus, the rate of permanent postoperative hypoparathyroidism ranges from $1.5 \%$ to $3.5 \%$, depending on the entity. These rates are in the upper range of the recent literature [10,19-23]. Since permanent postoperative hypoparathyroidism is a debilitating complication for the affected patients, even more attention should be paid in the future to avoid this complication. The rates of postoperative bleeding and wound infections requiring revision was comparatively low in the overall collective with $1.4 \%$ and $0.07 \%$, respectively $[10,19-23]$.

The present study has some drawbacks and some strengths. Although the data are prospectively documented in the StuDoQ/Thyroid registry and complete recording of all consecutive cases must be confirmed by the respective controlling of the participating centres every year, the current analysis has all of the limitations of a retrospective study. The 6-months follow-up data regarding RLNP and postoperative hypoparathyroidism were not available for about half of the patients. However, the present study based on the StuDoQ/Thyroid registry gives a clear picture of the actual trends of thyroid surgery for benign goitre in Germany, since almost 13,000 patients were documented in the previous 15 months.

In summary, the indication "exclusion of malignancy" or the so-called "diagnostic" (hemi)thyroidectomy can be made less liberally, if the recommended armamentarium of preoperative diagnostic options were to be fully used. Currently, thyroid resections are mostly hemi- or thyroidectomies, whereas partial resections play only a very minor role. The intraoperative standards to avoid injury of the RLN and the parathyroids are high, although postoperative hypoparathyroidism is still a substantial problem which should be focused on.

Author Contributions: Conceptualization, D.K.B., K.L., C.D., C.K., H.J.B.; methodology, software and project administration, H.J.B., C.K.; investigation and data curation, D.K.B., C.D., K.L., C.V., T.W., A.Z., H.J.B.; formal analysis, D.K.B., H.J.B., C.K.; writing-original draft preparation, D.K.B.; writing-review and editing, C.D., K.L., C.V., A.Z., T.W., H.J.B.

Funding: This research received no external funding.

Acknowledgments: We would like to thank all patients who gave their consent to be documented in the registry and all 83 departments who have contributed patients to the StuDoQ/Thyroid registry. Members of the StuDoQ/Thyroid study group (ranking according to the number of enrolled patients): Christian Freitag, Klinik für Chirurgie, Krankenhaus St. Joseph-Stift Dresden; Detlef Krenz, Klinik für Allgemein-, Viszeral-, Gefäß- und Thoraxchirurgie, Klinikum Dritter Orden München; Markus Wolfgang Büchler, Chirurgische Klinik, Krankenhaus Salem Heidelberg and Krankenhaus Sinsheim; Stefan Klozoris, Klinik für Allgemein- und Viszeralchirurgie, Evangelisches Johanniter-Krankenhaus Bonn; Said Saalabian, Klinik für Endokrine Chirurgie, DKD Wiesbaden; Martin Memming, Klinik für Allgemein-, Viszeral- und Gefäßchirurgie, Klinikum Robert Koch Gehrden; Hinrich Köhler, Chirurgische Klinik Herzogin Elisabeth Hospital Braunschweig; Christoph-Thomas Germer, Klinik für Allgemein-, Viszeral-, Gefäß- u. Kinderchirurgie Universitätsklinikum Würzburg; Nikolaus Steigemann, Klinik für Endokrine Chirurgie Krankenhaus Vilsiburg; Joachim Jähne, Klinik für Allgemeinund Viszeralchirurgie, Diakonie-Krankenhaus Henriettenstiftung Hannover; Knut A. Böttcher, Abteilung für Allgemein- und Viszeralchirurgie, Diakoniekrankenhaus Mannheim; Alfred Brütting, Chirurgische Klinik, Maltester Waldkrankenhaus St. Marien Erlangen; Hans Udo Zieren, Klinik für Allgemein-, Viszeral und Unfallchirurgie, St. Agatha-Krankenhaus Köln; Heimo Weih, Klinik für Allgemein- und Viszeralchirurgie, Asklepios Klinik Seligenstadt; Georg Pistorius, Klinik für Allgemein-, und Viszeralchirurgie, Klinikum des Landkreises Bamberg; Michael Heise, Klinik für Allgemein- und Viszeralchirurgie, Sana Klinikum Lichtenberg; Robert Schwab, Klinik für Allgemein-, Viszeral- und Thoraxchirurgie Bundeswehrkrankenhaus Koblenz; Katharina 
Schwarz, Chirurgische Klinik III, Lukaskrankenhaus Neuss; Reinhard Kasperk, Klinik für Allgemein-, Viszeralund Thoraxchirurgie, Luisenhospital Aachen; Peter Langer, Klinik für Allgemein-, Viszeral- und Thoraxchirurgie, Klinikum Hanau; Matthias Kemen, Klinik für Allgemein- und Viszeralchirurgie, Evangelisches. Krankenhaus Herne; Lutz Mirow, Klinik für Allgemein- und Viszeralchirurgie, Klinikum Chemnitz; Matthias Behrend, Klinik für Viszeral-, Thorax- und Gefäßchirurgie, Donau-Isar-Klinikum Deggendorf; Michael Schwarz-GPS-Zentrum für onkologische, endokrine und minimal invasive Chirurgie, Schilddrüsenzentrum Neu-Ulm; Andrea Beuleke, Klinik für Allgemein- und Viszeralchirurgie, Klinikum Großwedel; Mathias Löhnert, Klinik für Allgemeinund Viszeralchirurgie, Klinikum Bielefeld; Matthias Hoffmann, Klinik für Allgemein- und Viszeralchirurgie mit Sektion Proktologie, Raphaelsklinik Münster; Christoph Nies, Klinik für Klinik für Allgemein- und Viszeralchirurgie, Niels-Stensen-Klinikum Marienhospital Osnabrück; Christopher Hagel, Klinik für Allgemeinund Viszeralchirurgie, Marienhausklinikum Saarlouis-Dillingen; Harald Tigges, Klinik für Allgemein-, Viszeralund Gefäßchirurgie, Klinikum Landsberg am Lech; Friedrich Krings, Chirurgische Klinik I, Christophorus Kliniken Coesfeld; Jochen Schabram, Klinik für Endokrine Chirurgie, Asklepios Klinik Lich; Christoph-Andreas Jacobi, Klinik für Chirurgie, Dreifaltigkeit-Krankenhaus Wesseling; Jochen Schuld, Klinik für Allgemein- und Viszeralchirurgie, Knappschaftskrankenhaus Sulzbach; Christian Mönch, Klinik für Allgemein-, Viszeral- und Transplantationschirurgie, Westpfalz-Klinikum Kaiserslautern; Michael Ghadimi, Klinik für Allgemein-, Viszeralund Kinderchirurgie, Universitätsmedizin Göttingen; Christoph Prinz, Klinik für Allgemein-, Thorax- und Gefäßchirurgie, KMG Klinikum Güstrow GmbH; Stefan Train, Klinik für Allgemein- und Viszeralchirurgie, Johanniter-Krankenhaus Gronau; Karsten Ridwelski, Klinik für Allgemein- und Viszeralchirurgie, Klinikum Magdeburg gGmbH; Matthias Heuser, Klinik für Allgemein- und Viszeralchirurgie, St. Elisabeth Hospital Herten; Joachim Mellert, Klinik für Allgemein-, Viszeral- und Gefäßchirurgie, St. Ansgar-Krankenhaus Höxter; Thomas Simon, Klinik für Allgemein- und Viszeralchirurgie, GRN-Klinik Weinheim; Mark Jäger, Klinik für Allgemein-, Viszeral und MIC, Städtisches Klinikum Wolfenbüttel; Hans-Martin Schardey, Klinik für Allgemein-, Viszeral-, Gefäß- und Endokrine Chirurgie, Krankenhaus Agatharied; Joachim Heise, Klinik für Allgemein-, Viszeral- und Schilddrüsenchirurgie Bethlehem, Gesundheitszentrum Stollberg; Ernst Klar, Klinik für Allgemein-, Thorax-, Gefäß- und Transplantationschirurgie, Universitätsmedizin Rostock Berthold Schneider, Klinik für Allgemein- und Viszeralchirurgie, St. Marien-Hospital Bonn; Sebastian Hoffmann, Klinik für Allgemein- und Viszeralchirurgie, Marienkrankenhaus Bergisch-Gladbach; Michael Pauthner, Chirurgische Klinik I, Sana Klinikum Offenbach; Eberhard Gliesing, Klinik für Chirurgie, Asklepios Kliniken Schwalm-Eder, Melsungen; Nada Rayes, Klinik für Viszeral-, Transplantations-, Thorax- und Gefäßchirurgie, Universitätsklinikum Leipzig; Nico Schäfer, Klinik für Allgemein-, Viszeral- und Thoraxchirurgie, Klinikum Leverkusen gGmbH; Roland Albrecht, Klinik für Viszeral-, Minimalinvasive und Thorachirurgie, HELIOS-Klinikum Aue; Stefan Riedl, Allgemeinchirurgische Klinik, Alb-Fils Kliniken GmbH Göppingen; Reiko Wießner, Klinik für Allgemeine Chirurgie und Viszeralchirurgie, Bodden Klinik Ribnitz Damgarten; Christian Peiper, Abteilung Allgemeine- und Viszeralchirurgie, EVK Hamm Evangelisches Krankenhaus; Wilhelm Gross-Weege, Klinik für Allgemein- und Viszeralchirurgie, St. Elisabeth-Krankenhaus; Ullrich Fleck, Klinik für Allgemein-, Viszeralchirurgie, DRK-Krankenhaus Luckenwalde; Lutz Hausser, Klinik für Allgemein- und Viszeralchirurgie, Klinikum Oberallgäu, Klinik Immenstadt; Mario Dellanna, Klinik für Allgemein-, Viszeral- und minimalinvasive Chirurgie, St.-Antonius-Hospital Eschweiler; Matthias Becker, Chirurgische Klinik, Weißeritztal-Kliniken GmbH Freital; Peter Kienle, Klinik für Allgemein- und Viszeralchirurgie, Theresienkrankenhaus Mannheim; Jochen Klinnert, Klinik für Allgemein- und Viszeralchirurgie, Asklepios Klinik Parchim; Carsten J. Krones, Klinik für Allgemein-, Viszeral- und spezielle Viszeralchirurgie, Marienhospital Aachen; Matthias Pross, Klinik für Chirurgie, DRK-Krankenhaus Berlin-Köpenick; Albrecht Stier, Klinik für Allgemeinund Viszeralchirurgie, HELIOS-Klinik Erfurt; Ulrich Mittelkötter, Klinik für Allgemein- und Viszeralchirurgie, Katharinen-Hospital Unna; Karsten Junge, Klinik für Allgemein-, und Viszeralchirurgie, Rhein-Maas-Klinikum Aachen-Würselen; Mike-Ralf Langenbach, Klinik für Allgemein-, und Viszeralchirurgie und Koloproktologie, HELIOS St. Elisabeth-Klinik Oberhausen; Stefan Schmidbauer, Klinik für Chirurgie, Kreisklinik Wolfratshausen; Markus Koppenburg, Klinik für Allgemein- und Viszeralchirurgie, Cura Krankenhaus Bad Honnef; Bernhard Drummer, Klinik für Allgemeinchirurgie, Klinikum Forchheim; Niels Huschitt, Klinik für Allgemein-, Viszeralund Thoraxchirurgie, Bundeswehrkrankenhaus Berlin; Frank Klammer, Klinik für Allgemein-, Viszeral- und Thoraxchirurgie, St. Franziskus-Hospital Ahlen.

Conflicts of Interest: The authors declare no conflict of interest.

\section{References}

1. Statistisches Bundesamt (Destatis). Statistisches Bundesamt Fallpauschalenbezogene Krankenhausstatistik (DRG-Statistik). Operationen und Prozeduren der vollstationären Patientinnen und Patienten in KrankenhäusernAusführliche Darstellung; Statistisches Bundesamt (Destatis): Berlin, Germany, 2012.

2. Bartsch, D.K.; Luster, M.; Buhr, H.J.; Lorenz, D.; Germer, C.T.; Goretzki, P.E.; German Society for General and Visceral Surgery. Indications for the operative management of benign goiter in adults. Dtsch. Arztebl. Int. 2018, 115, 1-7. [PubMed]

3. AWMF-Leitlinie operative Therapie benigner Schilddrüsenerkrankungen. Available online: https://www. awmf.org/leitlinien/detail/11/088-007.html,onlineOctober2015 (accessed on 7 April 2019). 
4. Dralle, H.; Musholt, T.J.; Schabram, J.; Steinmüller, T.; Frilling, A.; Simon, D.; Goretzki, P.E.; Niederle, B.; Scheuba, C.; Clerici, T.; et al. German Association of Endocrine Surgeons practice guideline for the surgical management of malignant thyroid tumors. Langenbecks Arch. Surg. 2013, 398, 347-375. [CrossRef] [PubMed]

5. Musholt, T.J.; Bockisch, A.; Clerici, T.; Dotzenrath, C.; Dralle, H.; Goretzki, P.E.; Hermann, M.; Holzer, K.; Karges, W.; Krude, H.; et al. Update of the S2k-guidelines: Surgical treatment of benign thyroid diseases. Chirurg 2018, 89, 699-709. [CrossRef] [PubMed]

6. Sawka, A.M.; Carty, S.E.; Haugen, B.R.; Hennessey, J.V.; Kopp, P.A.; Pearce, E.N.; Sosa, J.A.; Tufano, R.P.; Jonklaas, J.; et al. American Thyroid Association Guidelines and Statements: Past, Present, and Future. Thyroid 2018, 28, 692-706. [CrossRef] [PubMed]

7. Gharib, H.; Papini, E.; Paschke, R.; Duick, D.S.; Valcavi, R.; Hegedüs, L.; Vitti, P.; AACE/AME/ETA Task Force on Thyroid Nodules. American Association of Clinical Endocrinologists, Associazione Medici Endocrinologi, and European Thyroid Association medical guidelines for clinical practice for the diagnosis and management of thyroid nodules: Executive summary of recommendations. J. Endocrinol. Investig. 2010, 33, 51-56. [CrossRef] [PubMed]

8. Wienhold, R.; Scholz, M.; Adler, J.R.; Nster, C.G.; Paschke, R. The management of thyroid nodules. A retrospective analysis of health insurance data. Dtsch. Ärztebl. Int. 2013, 110, 827-834. [PubMed]

9. Maneck, M.; Dotzenrath, C.; Dralle, H.; Fahlenbrach, C.; Paschke, R.; Steinmüller, T.; Tusch, E.; Jeschke, E.; Günster, C. Complications after thyroid surgery in Germany. Chirurg 2017, 88, 50-57. [CrossRef] [PubMed]

10. Dralle, H.; Sekulla, C.; Stang, A.; Sekulla, C.; Rusner, C.; Lorenz, K.; Machens, A. Thyroid surgery in Germany. Less operations, changing strategies, less complications. Chirurg 2014, 85, 236-245. [CrossRef] [PubMed]

11. Dralle, H.; Lorenz, K.; Machens, A. State of the art: Surgery for endemic goiter-A plea for individualizing the extent of resection instead of heading for routine total thyroidectomy. Langenbecks Arch. Surg. 2011, 396, 1137-1143. [CrossRef] [PubMed]

12. Cibas, E.S.; Ali, S.Z. The Bethesda system for reporting thyroid cytopathology. Am. J. Clin. Pathol. 2009, 132, 658-665. [CrossRef] [PubMed]

13. Agency for Healthcare Research and Quality Rockville MD. HCUP National Inpatient Sample (NIS). Healthcare Cost and Utilization Project (HCUP). [Internet]. HCUP Natl. Inpatient Sample NIS Healthc Cost Util Proj. HCUP. 2012. Available online: www.hcup-us.ahrq.gov/nisoverview.jsp (accessed on 15 March 2017).

14. Goretzki, P.E.; Schwarz, K.; Ozolins, A.; Luyven, E.; Lammers, B. Surgical treatment of the suspicious thyroid nodule. Nuklearmediziner 2016, 39, 218-226.

15. Dralle, H.; Sekulla, C.; Lorenz, K.; Thanh, P.N.; Schneider, R.; Machens, A. Loss of the nerve monitoring signal during bilateral thyroid surgery. Br. J. Surg. 2012, 99, 1089-1095. [CrossRef] [PubMed]

16. Phelan, E.; Schneider, R.; Lorenz, K.; Dralle, H.; Kamani, D.; Potenza, A.; Sritharan, N.; Shin, J.; Randolph, G.W. Continuous vagal IONM prevents recurrent laryngeal nerve paralysis by revealing initial EMG changes of impending neuropraxic injury: A prospective, multicenter study. Laryngoscope 2014, 24, 1498-1505. [CrossRef] [PubMed]

17. Dralle, H.; Sekulla, C.; Haerting, J.; Timmermann, W.; Neumann, H.J.; Kruse, E.; Grond, S.; Mühlig, H.P.; Richter, C.; Voß, J.; et al. Risk factors of paralysis and functional outcome after recurrent laryngeal nerve monitoring in thyroid surgery. Surgery 2004, 136, 1310-1322. [CrossRef] [PubMed]

18. Bergenfelz, A.; Jansson, S.; Kristoffersson, A.; Mårtensson, H.; Reihnér, E.; Wallin, G.; Lausen, I. Complications to thyroid surgery: Result as reported in a database from a multicentre audit comprising 3.660 patients. Langenbecks Arch. Surg. 2008, 393, 667-673. [CrossRef] [PubMed]

19. Diener, M.K.; Seiler, C.M.; Von Frankenberg, M.; Rendel, K.; Schüle, S.; Maschuw, K.; Riedl, S.; Rückert, J.C.; Eckmann, C.; Scharlau, U.; et al. Vascular clips versus ligatures in thyroid surgery-Results of a multicenter randomized controlled trial (CLIVIT trial). Langenbecks Arch. Surg. 2012, 397, 1117-1126. [CrossRef] [PubMed]

20. Thomusch, O.; Sekulla, C.; Billmann, F.; Seifert, G.; Dralle, H.; Lorenz, K.; Prospective Evaluation Study of Thyroid Surgery (PETS 2) Study Group. Risk profile analysis and complications after surgery for autoimmune thyroid disease. Br. J. Surg. 2018, 105, 677-685. [CrossRef] [PubMed]

21. Blanchard, C.; Pattou, F.; Brunaud, L.; Hamy, A.; Dahan, M.; Mathonnet, M.; Volteau, C.; Caillard, C.; Durand-Zaleski, I.; Mirallié, E.; et al. Randomized clinical trial of ultrasonic scissors versus conventional haemostasis to compare complications and economics after total thyroidectomy (FOThyr). BJS Open 2017, 9, 2-10. [CrossRef] [PubMed] 
22. Cavicchi, O.; Caliceti, U.; Fernandez, I.J.; Ceroni, A.R.; Marcantoni, A.; Sciascia, S.; Sottili, S.; Piccin, O. Laryngeal neuromonitoring and neurostimulation versus neurostimulation alone in thyroid surgery: A randomized clinical trial. Head Neck 2012, 34, 141-145. [CrossRef]

23. Rayes, N.; Steinmüller, T.; Schröder, S.; Klötzler, A.; Bertram, H.; Denecke, T.; Neuhaus, P.; Seehofer, D. Bilateral subtotal thyroidectomy versus hemithyroidectomy plus subtotal resection (Dunhill procedure) for benign goiter: Long-term results of a prospective, randomized study. World J. Surg. 2013, 37, 84-90. [CrossRef]

(C) 2019 by the authors. Licensee MDPI, Basel, Switzerland. This article is an open access article distributed under the terms and conditions of the Creative Commons Attribution (CC BY) license (http://creativecommons.org/licenses/by/4.0/). 